NASA Technical Memorandum 100295

AIME Paper A88-23

\title{
Mixing Fuel Particles for Space Combustion Research Using Acoustics
}

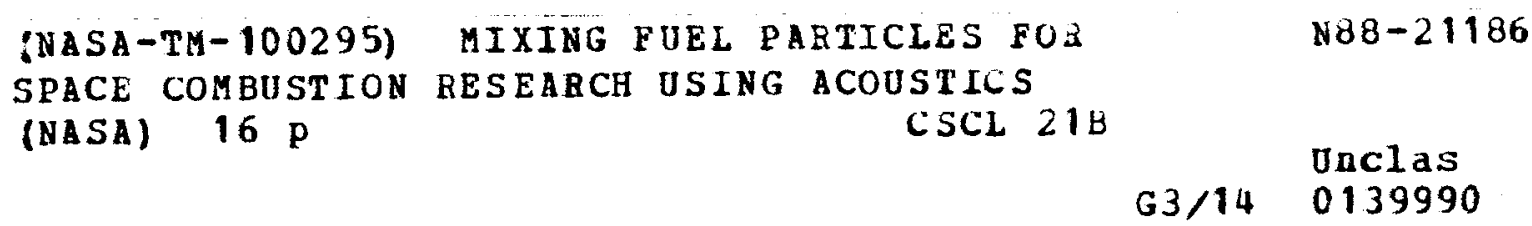

Robert J. Burns, Jerome A. Johnson, and Robert B. Klimek

Lewis Research Center

Cleveland, Ohio

Prepared for the

Second International Symposium on Experimental Methods for Microgravity Materials Science Research sponsored by the Metallurgical Society of AIME

Phoenix, Arizona, January 25-29, 1988 
MIXING FUEL PARTICLES FOR SPACE COMBUSTION RESEARCH USING ACOUSTICS

Robert J. Burns, Jerome A. Johnson, and Robert B. Klimek

National Aeronautics and Space Administration

Lewis Research Center

Cleveland, Ohio 44135

\section{ABSTRACT}

Part of the microgravity science to be conducted aboard the Shuttle (STS) involves combustion using solids, particles, and liquid droplets. The central experimental facts needed for characterization of premixed quiescent particle cloud flames cannot be adequately established by normal gravity studies alone. This paper describes the experimental results to date of acoustically mixing a prototypical particulate, lycopodium, in a $5 \mathrm{~cm}$ diameter by $75 \mathrm{~cm}$ long flame tube aboard a Learjet aircraft flying a 20-sec low-gravity trajectory. Photographic and light detector instrumentation combine to measure and characterize particle cloud uniformity.

\section{INTRODUCTION}

A study of flame propagation and extinction of premixed flames has occupied a position of central interest in combustion science. Microgravity experimentation offers the opportunity to establish uniform quiescent clouds of particulates and to study their roles in two-phase flame propagation and extinction processes. It can be shown (Ref. 1) that theoretical representation of the microgravity two-phase flames is far more tractable than those that are required for normal gravitational conditions. Details of combustion experiments planned for microgravity environments have been discussed elsewhere (Ref. 2). The important property of a fuel particle cloud, being quiescent and uniformly mixed, has been impossible to realize prior to the space exploration era. Gravity, turbulence properties following mixing, and free convection processes, are all present deficiencies that 
promise to be manageable with present microgravity space laboratory facilities. This paper describes efforts to date to verify that lycopodium fuel can be adequately mixed in a standard flame tube in a near zero-gravity environment prior to proceeding to extensive combustion tests aboard the Shuttle (STS). The science requirements for the STS Particle Cloud Combustion Experiment (PCCE) listed here were used to guide the development test program conducted in the NASA Lewis Research Center microgravity facilities:

(1) Distribution of particles along the tube length (concentration uniformity) - within \pm 5 percent

(2) Number of particles in given volume (equivalence ratio $\Phi$ ) - set point \pm 5 percent, where $\Phi=\frac{\text { actual fuel-air ratio }}{\text { stoichiometric fuel-air ratio }}$

(3) Set point pressure $-1.0 \times 10^{5} \mathrm{~Pa} \pm 5$ percent

(4) Set point temperature $-21 \pm 6{ }^{\circ} \mathrm{C}$

(5) Air composition in tube $-21 \pm 1$ percent oxygen; 79 percent nitrogen

(6) Gravity level (3 axis)

Set point: $5 \times 10^{-4} \mathrm{~g}$ (nominal)

Stability: $\quad \pm 1 \times 10^{-4} \mathrm{~g}$

Recording frequency: $1 \mathrm{~Hz}$

\section{APPARATUS \\ Experimental Test Package}

The test package consists of a single flame tube assembly and the instrumentation, controls, and data recorders to collect the data. The STS flight experiment will have eight flame tube assemblies representing eight fuel-air ratios $(\Phi)$; and the test data will be similarly measured and recorded. Flame tube (see Fig. 1). - A $75 \mathrm{~cm}$ long by $5 \mathrm{~cm}$ diameter flame tube was designed to represent a standard $100 \mathrm{~cm}$ flame tube because of space 
limitations on the STS. Lexan was chosen for the tube walls because of its nonfragile properties along with its light transmitting characteristics needed by the light detectors to sense the presence of fuel particles, and to photograph the flames of combustion. A very light plating of gold vapor deposited on the inside walls of the tube is thought to be beneficial in suppressing particle-wall adhesion because of the electrical properties of gold. The enlarged $6.0 \mathrm{~cm}$ diameter section at the igniter end of the tube is called the ignition chamber because it was designed to enhance the ignition of the fuel particles. Figures 2 and 3 show the eight-tube flight assembly and the location of the experiment on the Material Science Laboratory (MSL). Diaphragms. - Diaphragms were required at each end of the flame tube to contain the fuel particles during mixing, a feature which would then assure that the fuel-air ratio is known. The diaphragms are glued to a ring which is clamped between the tube flanges. Rubber 0-rings are used to seal the flanges. Aluminized mylar was chosen for the diaphragm material because of its toughness and durability in responding to the deflections caused by acoustic energies during the fuel mixing function. The igniter diaphragm is ruptured during the fuel ignition function, and this combustion of the mylar must be compatible with the subsequent combustion of the fuel, i.e., the oxygen $\left(\mathrm{O}_{2}\right)$ consumed during ignition must not exceed 2 percent of the available oxygen in the tube. Diaphragms of various degrees of tightness were made by a vacuum-mold process involving heat to shape them.

Igniter. - The igniter is constructed of a $25 \mathrm{~cm}$ long by $0.013 \mathrm{~cm}$ diameter nichrome wire wrapped around $100 \mathrm{mg}$ of nitrocellulose (guncotton).

Heat exchanger. - The heat exchanger consists of a sintered ceramic disc which, when located in the exhaust path of the burned gasses, reduces the gas temperature and thus the rate of pressure buildup within the tube. 
Exhaust bag. - The exhaust bag is made of aluminized mylar and was designed for STS to expand and collect expanded combustion gases and products with a minimum resistance to gas expansion. When the exhaust gas cools the bag collapses.

Particle detector. - Four particle detectors spaced along the $75 \mathrm{~cm}$ tube length is considered adequate in establishing concentration uniformity of particles prior to combustion. A particle detector consists of a light emitting diode providing a well collimated beam. It is made of Ga/Al/As and its operating wavelength is centered at about $820 \mathrm{~nm}$ where the temperature dependence of the silicon (ultraviolet series) detector is less than 0.05 percent $/{ }^{\circ} \mathrm{C}$. Calibration of each detector for differences in light transmissivity through the flame tube was essential for each flame tube tested.

Speaker. - The speaker was an off-the-shelf $5-W, 10.2 \mathrm{~cm}$ woofer with an $8 \Omega$ impedance and a frequency response of 55 to $5000 \mathrm{~Hz}$. It was driven by a digital oscillator and 45-W current limited amplifier.

Fuel. - Lycopodium was chosen as a first choice for study because of particle size uniformity, batch reproducibility, low ash content, and compositional correspondence to coals of interest. It is a naturally occurring spore having a particle size of about $30 \mu \mathrm{m}$ and a considerable heat of combustion. An elemental analysis is given below:

\section{LYCOPODIUM POWDER ANALYSIS, $a, b$}

$$
\text { wt } \%
$$

Carbon................... . . 65.8

Oxygen . . . . . . . . . . . . . . . . 21.9

Hydrogen . . . . . . . . . . . . . . . . 9.6

Ash . . . . . . . . . . . . . . . 1.3

Nitrogen . . . . . . . . . . . . . . . 1.2

Sulfur . . . . . . . . . . . . . . 0.2

aU.S. Bureau of Mines. Methods of Analyzing and Testing Coal and Coke. BuMines Bull. 638, 1967, 82 pp.

bComposition determined on the sample as received; includes 3.24 wt \% water. Heating value is 28886 Btu/kgm on this basis when the lycopodium powder is burned in a calorimeter. 
Low-Gravity Facilities

A 2.2-Second Drop Tower and a Learjet modified for higher g- loading were used at the NASA Lewis Research Center to test the acoustic mixing techniques described herein. The drop tower is $30.5 \mathrm{~m}$ tall, includes an aerodynamic shield surrounding the test rig, and uses a $2.2 \mathrm{~m}$ deep sand pit to absorb the impact loads $(\sim 30 \mathrm{gs})$. The low gravity achievable during the drop is $1 \times 10^{-5} \mathrm{~g}$.

The low gravity profile of the Learjet is shown in Fig. 4. The gravity levels are generally less than $0.01 \mathrm{~g}$ for 5 to $8 \mathrm{sec}$ continuously and less than $0.05 \mathrm{~g}$ for $15 \mathrm{sec}$ continuously. The pilots achieve these by nulling the accelerations in the three primary axes. The inherent accuracy of the accelerometer monitoring system is approximately $\pm 0.005 \mathrm{~g}$.

A rigid sealed end cap, $6.35 \mathrm{~cm}$ diameter by $19 \mathrm{~cm}$ long was used in place of an exhaust bag in flights 3 and 9 to maintain atmospheric pressure in the flame tube during aircraft altitude changes. In flight 11 a sealed chamber was used as shown in Fig. 5, similarily, to prevent pressure changes from loading the diaphragms.

\section{Selection of Mixing Frequencies}

Attempts were made during this test program to optimize the acoustic frequencies furnished by the radio speaker at one end of the flame tube. Theoretically, a longitudinal sound wave produced by a speaker at the end of the flame tube sets the two mylar diaphragms in vibration (Fig. 1). In order to realize a homogeneous cloud throughout the flame tube, it was theorized by the principal investigator that first vigorous then gentle mixing (macromixing and micromixing) must first be demonstrated in ground-based experiments. The diaphragms at each end of the tube alter the waves that travel through the gas in the flame tube. Points of high acoustic pressure variation, corresponding to the position of nodes, causes a high density pattern of lycopodium powder (Ref. 3). In a classical closed tube (one end open) the distance between 
adjacent nodes and antinodes is one-fourth wavelength $(\lambda)$. Therefore, the wavelength of the fundamental standing wave in a closed column is four times the length of the column. The wavelength is inversely proportional to frequency $(\lambda=V / \nu)$ at constant speed. The first overtone, or third harmonic in the tube, creates additional nodes and antinodes.

The effects of the first overtone were studied in these tests by warbling between the resonant frequency and the first overtone frequency. The fuel particle mixing achievable in the Particle Cloud Combustion Experiment can be somewhat predictable based on these basic acoustics laws, however, since the flame tube has flexible diaphragms at each end, and a porous heat exchanger in the exhaust end, the nodes and antinodes are difficult to model. For this reason, the mixing frequencies used in the $0-g$ tests were selected from $1-g$ tests in which the powder action appeared greatest to the observer and sound levels were maximum as measured with a sound power level meter.

\section{Diaphragm Tightness Selection}

Diaphragm development tests were conducted to show the effects of diaphragm tightness on mixing in a vertical tube in $1-g$. The diaphragms are classified into three categories: tight $(0.13 \mathrm{~cm} \pm 0.03)$, medium $(0.19 \mathrm{~cm} \pm 0.06)$, and loose $(0.32 \mathrm{~cm} \pm 0.08)$. The method used to measure the diaphragm deflections is shown in Fig. 6. Figure 7 contains the results of the tests conducted to determine which diaphragms produced the greatest cloud height in the tube. A $5 \mathrm{~W}$ speaker mounted at the bottom of the tube was operated at the resonant frequency which was determined for each diaphragm combination.

\section{Experimental Configurations}

Table I lists the test conditions for three experiments on the Learjet and a reference to the plotted results in addition to the operator observations. The list includes: amount and location of fuel loaded into the flame tube, diaphragm tightness, speaker power, orientation of the flame tube 
in the aircraft fuselage, speaker frequencies, and the warble rate applied to the two frequencies. The acoustic speaker was turned on in all cases when the zero-g condition was realized by the operator.

The quantity of fuel used in these tests represented rich mixtures that could be easily observed and photographed. The fuel location in flight 9 (tube mounted parallel to the aircraft z-axis) was at the bottom of the tube. Previous tests in the 2.2 second drop tower had indicated insufficient time to get the powder moved from one end of the tube to the other. In flights 3 and 11 the fuel was initially spread along the tube length prior to the flight; the tube in both cases being mounted horizontally in the aircraft. The tightness of the diaphragms was also to be studied and compared to results found in $1-g$ and $2.2 \mathrm{sec}$ drop tower tests. The speaker power variation was selected to obtain the effects of more particle agitation. Only the first mixing trajectory for each flight is reported here to minimize the uncertainty of powder location at the beginning of the test. The frequencies listed were determined in $1-g$ using the procedures described on page 4 . The presence of an exhaust bag and loose diaphragms for flight 11 , in lieu of a rigid sealed cap, resulted in lower resonant and first overtone frequencies. The operator observations recorded after each trajectory are listed to supplement powder action not visible in the film strips or video tapes and to better understand the mixing action.

\section{Photography}

A $16 \mathrm{~mm}$ camera recorded the mixing tests of flights 3 and 9 at $100 \mathrm{fps}$. In flight 11 , a hand-held high resolution video camera was used to record the results.

\section{RESULTS}

The results of the Learjet mixing tests were recorded using three simultaneous methods; operator observation, high-speed photography or high 
resolution video, and light beam attenuation (detector). A second operator observed the mixing to a lessor extent. The operator observations are listed in Table I. The detector plots are shown in Figs. 8 to 10, representing flights 9,3 , and 11 , respectively.

In flight 9 where the tube was mounted in a vertical plane perpendicular to the flight path, the particle cloud looked dense and rose $33 \mathrm{~cm}$ from the speaker diaphragm which was located at the bottom. Wisps of particles could be seen above the $33 \mathrm{~cm}$ height. The detector plot ( $F i g .8$ ) shows that the cloud was in a ball and moved past detector 4 to detector 3 and then dropped to detector 4 again. Detectors 1 and 2 showed very little light attenuation, and, therefore, that the cloud failed to reach beyond $33 \mathrm{~cm}$. The filmstrip confirms this statement.

In flight 3 where the tube was mounted in the horizontal plane and parallel to the flight path, the particle cloud appeared to the observer to fill the tube. The detector plot (Fig. 9) shows that better mixing was achieved when the particles were spread evenly along the tube. The 100 percent attenuation on detectors No. 2 and 3 is an indication that saturation had occurred, either on the wall or in the beam. The differences in detector readings is attributed to the initial fuel quantity varying with position along the tube. Detector 4 was inopertive. The film strip confirms the full tube cloud when the operator used a flashlight to illuminate the cloud.

In flight 11, where the tube was mounted in a horizontal plane and perpendicular to the flight path, the results were similar to flight 3 , however, there was likely a greater uneveness in the initial location of the fuel along the tube. Here detector 4 is saturated for a period of 4 to 6 sec. The hand-held video shows fairly violent mixing throughout the tube. In trajectory 1 of flight 11 , the acoustic system was not energized, and it was observed and verified by the detectors that the powder did not become airborne 
when the aircraft entered zero-g. In both horizontal tube tests, the particles gradually migrated away from the speaker end of the tube in successive trajectories. (Successive trajectory data not presented.) Also, it was evident that some particles became attached to the tube wall. This adhesion condition worsened as the total mixing time accumulated with successive aircraft trajectories. However, in recent findings (Ref. 4), the authors suggest that the particle-wall attachment and the cluster growth problems may be effectively solved using $\alpha$ sources to reduce electrostatic adhesion.

\section{SUMMARY OF RESULTS}

1. Most energetic mixing was achieved with loose diaphragms near the speaker end of the tube.

2. Particle adhesion conditions worsened as the total mixing time accumulated with successive aircraft trajectories.

3. Better mixing was achieved when the particles were spread evenly along the tube placed in the horizontal position.

4. In the horizontal tube mixing tests the particles gradually migrated away from the speaker end of the tube with successive trajectories.

\section{REFERENCES}

1. A.L. Berlad: Paper IAF-83-141, American Institute of Aeronautics and Astronautics, New York, 1983.

2. A.L. Berlad and N.D. Joshi: Acta Astronautica, 1985, vol. 12, pp. 539-545.

3. H.O. Hooper and P. Gwyne: Physics and the Physical Perspective, 2nd ed., Harper \& Row, New York, 1980.

4. A.L. Berlad, N.D. Joshi, H. Ross, and R. Klimek: AIAA 87-0577, 1987. 
TABLE I. - EXPERIMENT CONF IGURATIONS/RESULTS

\begin{tabular}{|c|c|c|c|c|c|c|c|c|c|c|c|}
\hline \multirow{2}{*}{$\begin{array}{l}\text { flight } \\
\text { number }\end{array}$} & \multirow{2}{*}{$\begin{array}{c}\text { Fuel } \\
\text { quantity, } \\
\Phi\end{array}$} & \multirow{2}{*}{$\begin{array}{l}\text { Diaphragm } \\
\text { tightness, } \\
\mathrm{cm}\end{array}$} & \multirow{2}{*}{$\begin{array}{l}\text { Flame tube } \\
\text { axis in } \\
\text { fuselage }\end{array}$} & \multirow{2}{*}{$\begin{array}{l}\text { Fuel } \\
\text { location, } \\
\text { pretest }\end{array}$} & \multirow{2}{*}{$\begin{array}{c}\text { Speaker } \\
\text { power, } \\
\text { W }\end{array}$} & \multirow{2}{*}{$\begin{array}{l}\text { Trajec- } \\
\text { tory } \\
\text { number }\end{array}$} & \multirow{2}{*}{$\begin{array}{l}\text { Fre- } \\
\text { quency, } \\
\mathrm{Hz}\end{array}$} & \multirow{2}{*}{$\begin{array}{c}\text { Warble } \\
\text { rate, } \\
\mathrm{Hz}\end{array}$} & \multirow{2}{*}{$\begin{array}{l}\text { Timing of } \\
\text { speaker- } \\
\text { turn-on, } \\
\text { TEsec }\end{array}$} & \multicolumn{2}{|c|}{ Results } \\
\hline & & & & & & & & & & $\begin{array}{l}\text { Detector } \\
\text { plot } \\
\text { figure }\end{array}$ & $\begin{array}{l}\text { Operator } \\
\text { observations }\end{array}$ \\
\hline 9 & 3.0 & $\begin{array}{c}0.13 \\
\text { (tight) }\end{array}$ & $\begin{array}{l}\text { Vertical, } \\
\text { parallel to } \\
\text { to Z-axis } \\
\text { speaker at } \\
\text { bottom }\end{array}$ & $\begin{array}{l}\text { On speaker } \\
\text { diaphragin }\end{array}$ & 20 & 1 & $170 / 340$ & 0.5 & $I-0$ & 8 & $\begin{array}{l}\text { Dense cloud, } \\
\text { cloud height } \\
33 \mathrm{~cm}\end{array}$ \\
\hline 3 & 5.2 & $\begin{array}{c}0.13 \\
\text { (tight) }\end{array}$ & $\begin{array}{l}\text { Horizontal, } \\
\text { parallel } \\
\text { to } x \text {-axis } \\
\text { speaker aft }\end{array}$ & $\begin{array}{l}\text { Spread } \\
\text { along } \\
\text { tube } \\
\text { length }\end{array}$ & 15 & 1 & $170 / 0$ & -- & $T-0$ & 9 & $\begin{array}{l}\text { Cloud fills } \\
\text { tube, No. } 4 \\
\text { detector } \\
\text { inoperative }\end{array}$ \\
\hline 11 & 3.0 & $\begin{array}{c}0.38 \\
(7005 e)\end{array}$ & $\begin{array}{l}\text { Horizontal, } \\
\text { parallel } \\
\text { to Y-axis } \\
\text { speaker on } \\
\text { port side }\end{array}$ & $\begin{array}{l}\text { Spread } \\
\text { along } \\
\text { tube } \\
\text { length }\end{array}$ & 20 & 2 & $142 / 320$ & 0.5 & $T-0$ & 10 & $\begin{array}{l}\text { Cloud fills } \\
\text { tube }\end{array}$ \\
\hline
\end{tabular}

asee Fig. 6.

$c_{T}=$ zero-g entry time.

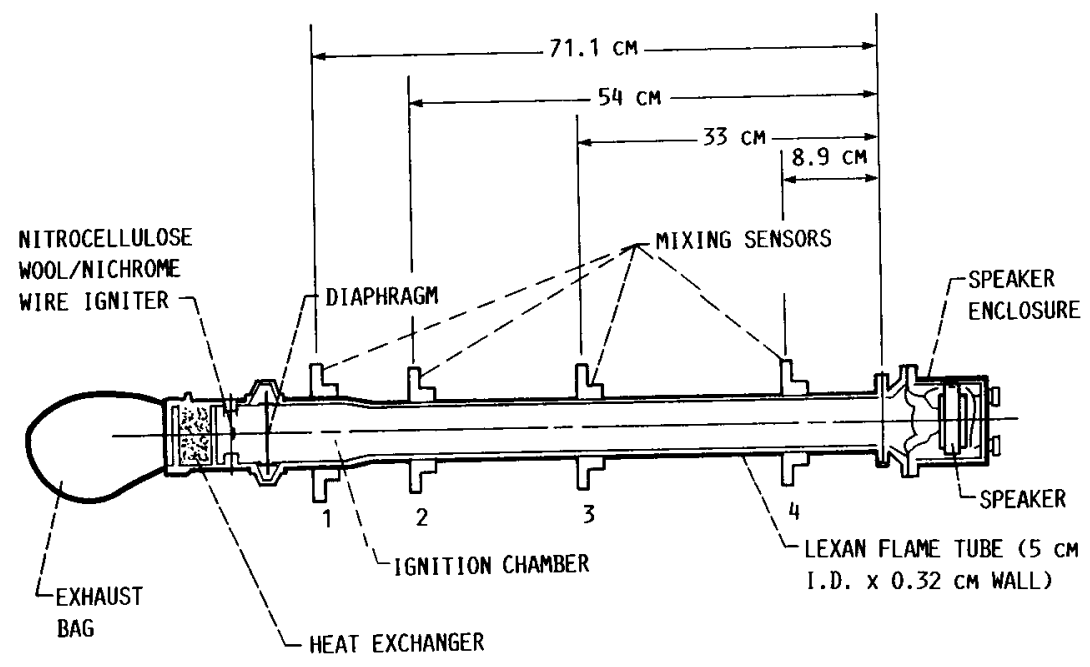

FIGURE 1. - FLAME TUBE ASSEMBL.Y. 


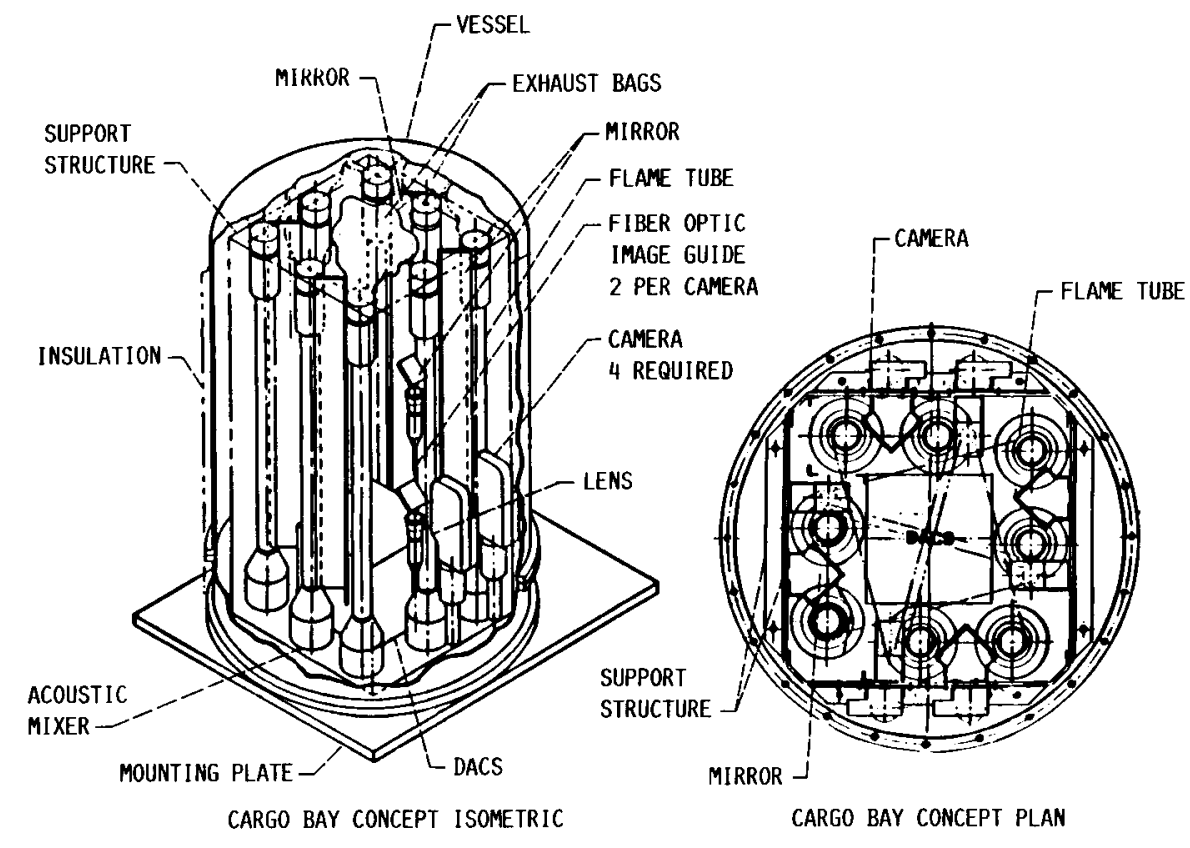

FIGURE 2. - EIGHT-TUBED SEALED CONTAINER. PARTICLE CLOUd COMBUSTION EXPERIMENT.

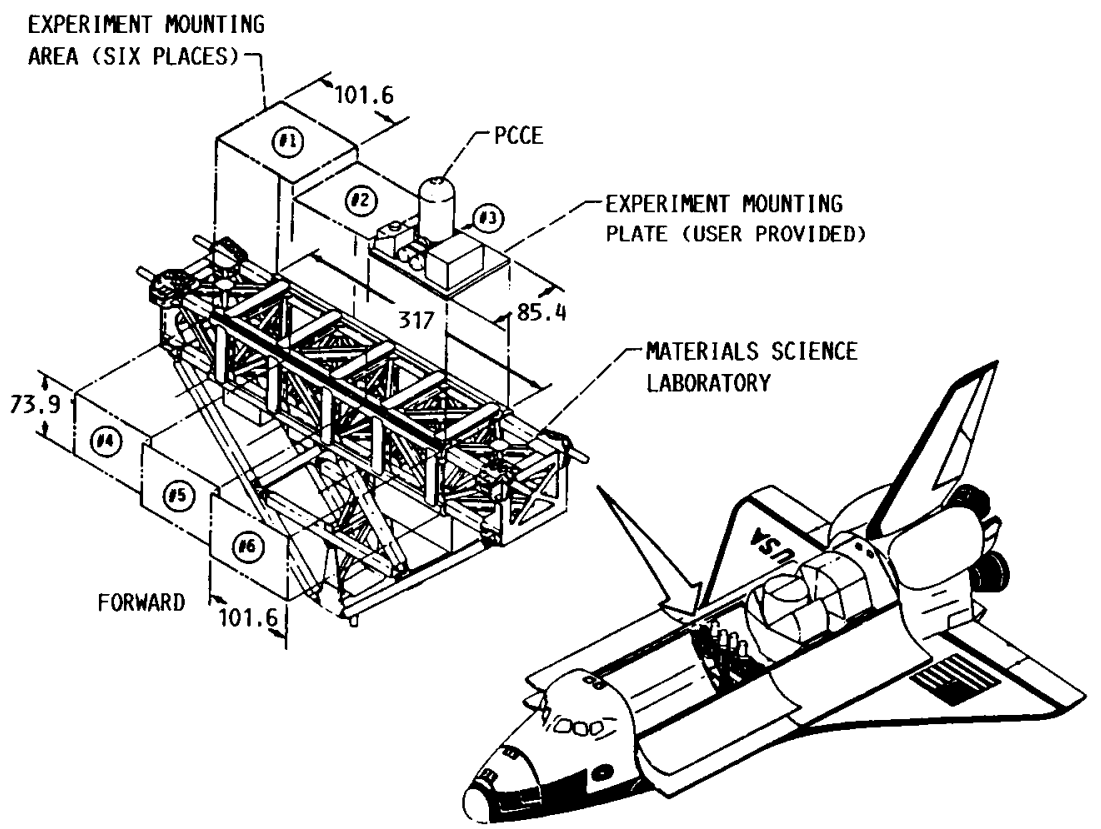

FIGURE 3. - PARTICLE CLOUD COMBUSTION EXPERIMENT. (MEASUREMENTS ARE IN (ENTIMETERS.) 

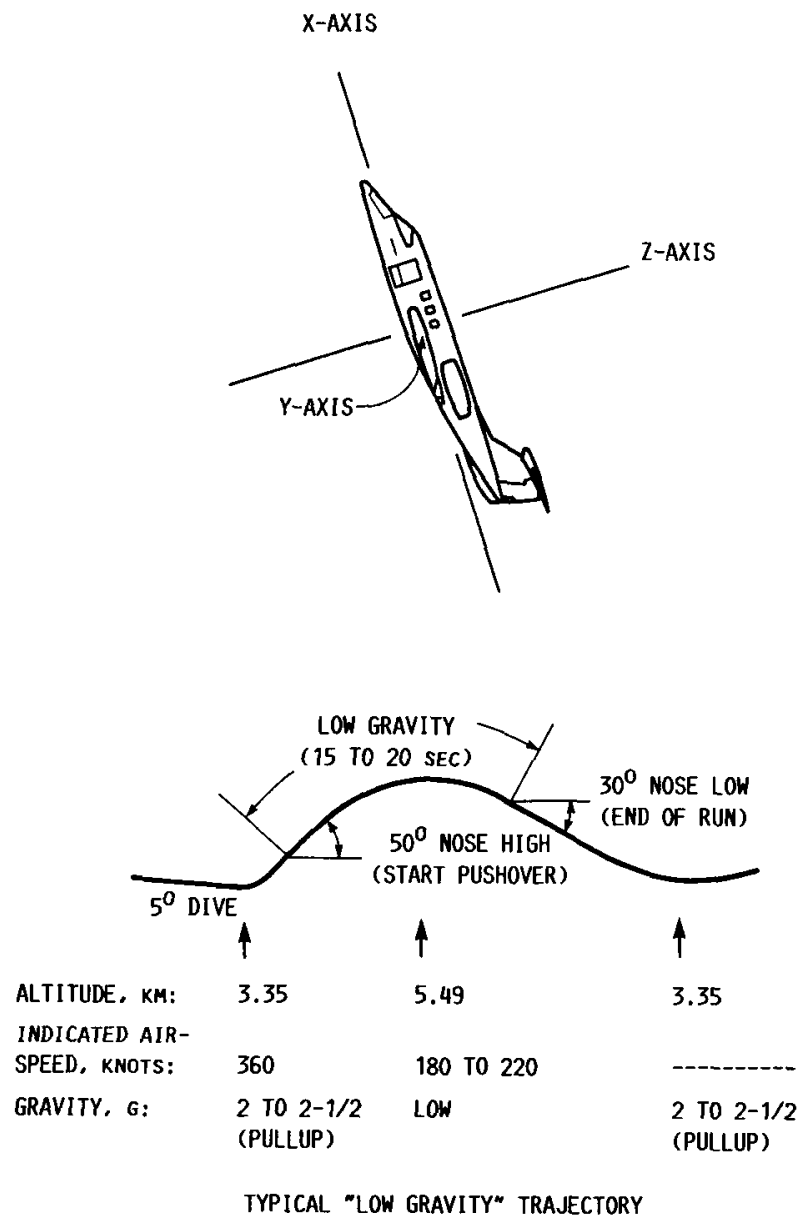

FiguRE 4. - LEARJET LOW-GRAVITY FACILITY $-10^{-2}$ g.

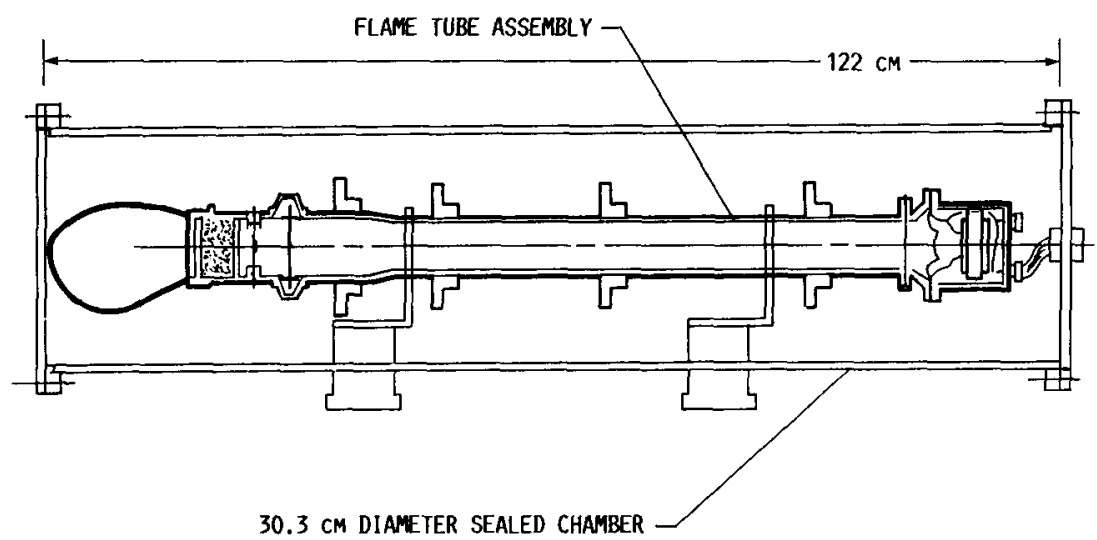

FIGURE 5. - LEARJET ACOUSTIC MIXER EXPERIMENT. 
- sPeaker at bottom

- FUEl loADED ON lower diaphragm

\begin{tabular}{c|c|c|c|}
\cline { 3 - 4 } & $\mathrm{t}$ & $\mathrm{m}$ & $\ell$ \\
\hline $\mathrm{T}$ & 3.8 & 2.5 & 2.5 \\
\hline $\mathrm{M}$ & 7.6 & 13.3 & 10.2 \\
\hline $\mathrm{L}$ & 15.2 & 22.9 & 31.8 \\
\hline
\end{tabular}

T, t, (TIGHT) $= \pm 0.13 \mathrm{~cm}$

M. m. (MEDIUM) $= \pm 0.19 \mathrm{cM}$

L.l. (LOOSE) $= \pm 0.32 \mathrm{~cm}$

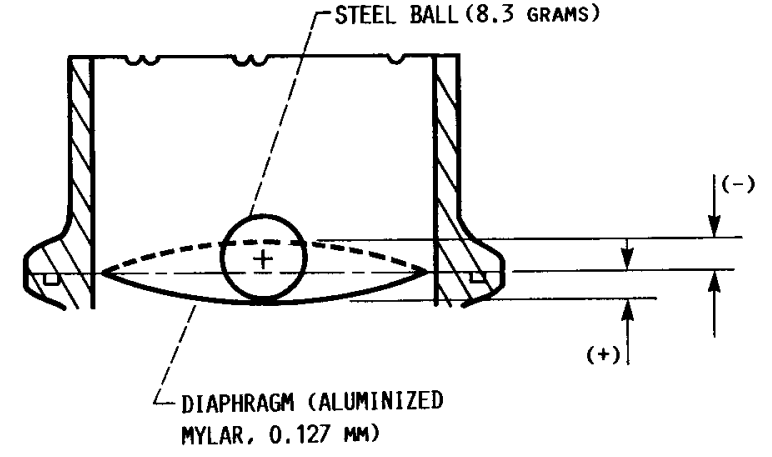

FIGURE 6, - DIAPHRAGM MEASUREMENT METHOD.

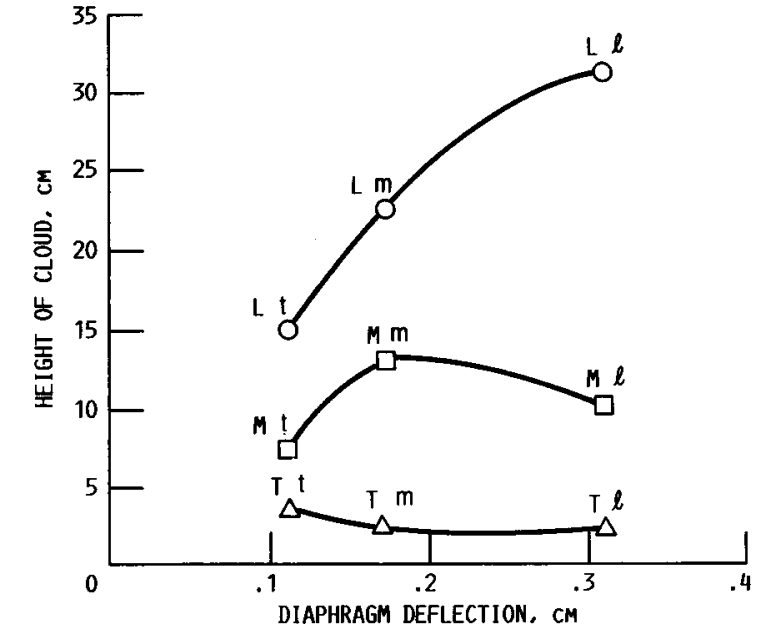

FIGURE 7. - HEIGHT OF CLOUD IN VERTICAL TUBE, 1 g VERSUS DIAPHRAGM DEFLECTION, CM.

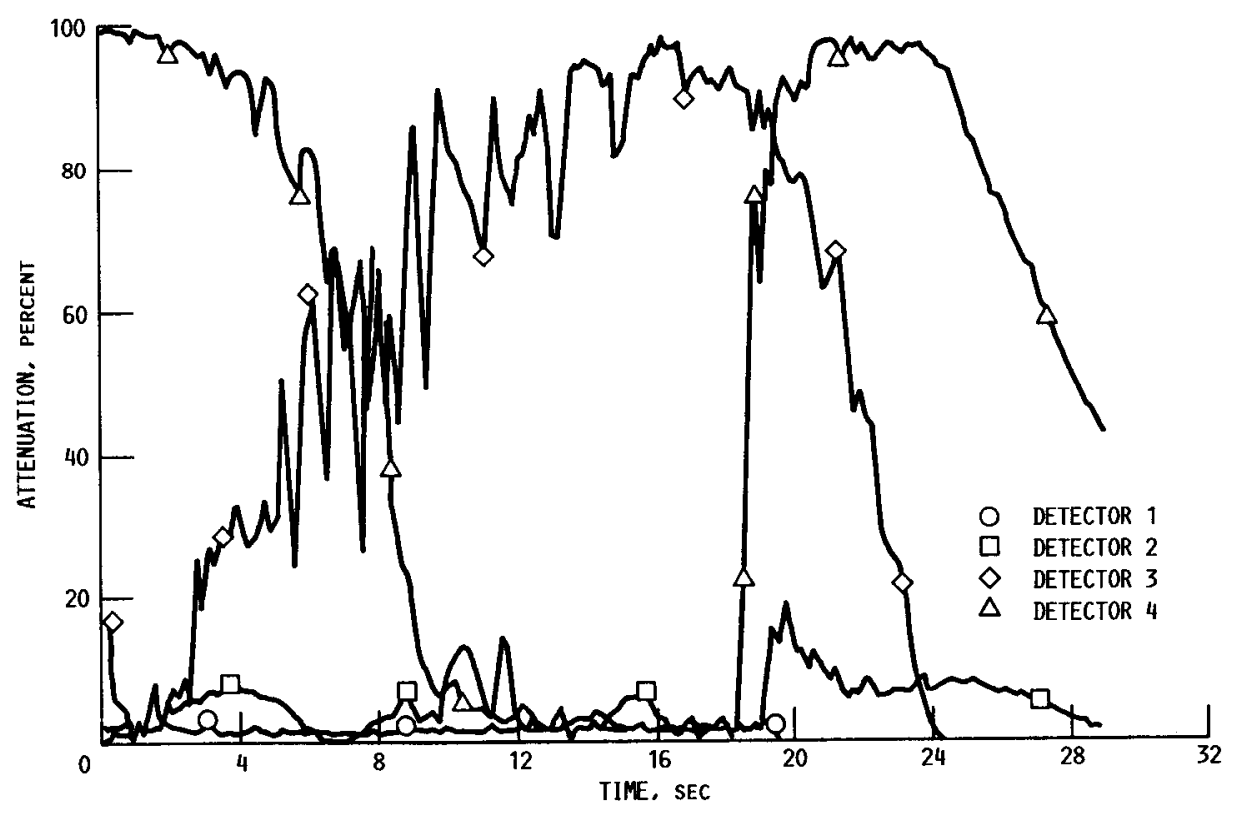

Figure 8. - Light beAM ATtenuAtion Versus time. Vertical tUBE, Z-AXIS. 


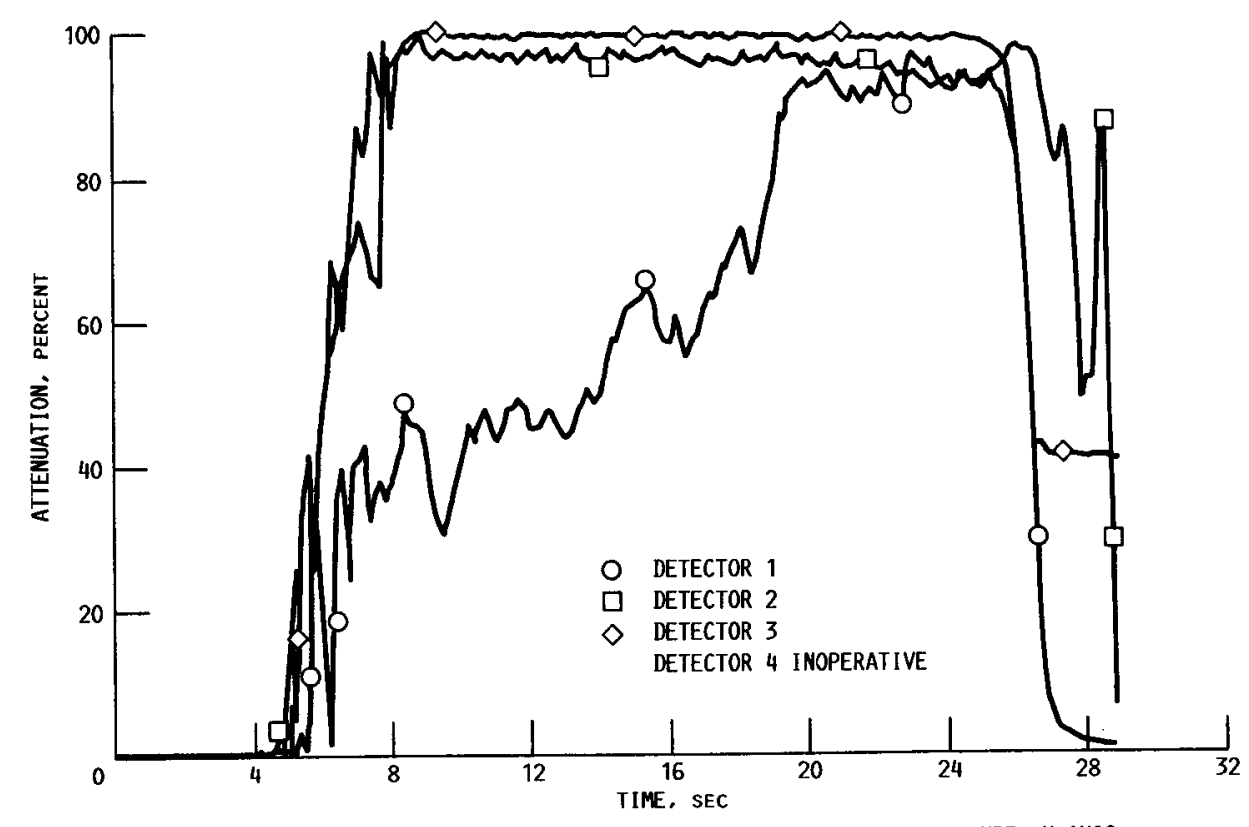

Figure 9. - Light BEAM ATTENUATION VERSUS TIME. HORIZONTAL TUBE, X-AXIS.

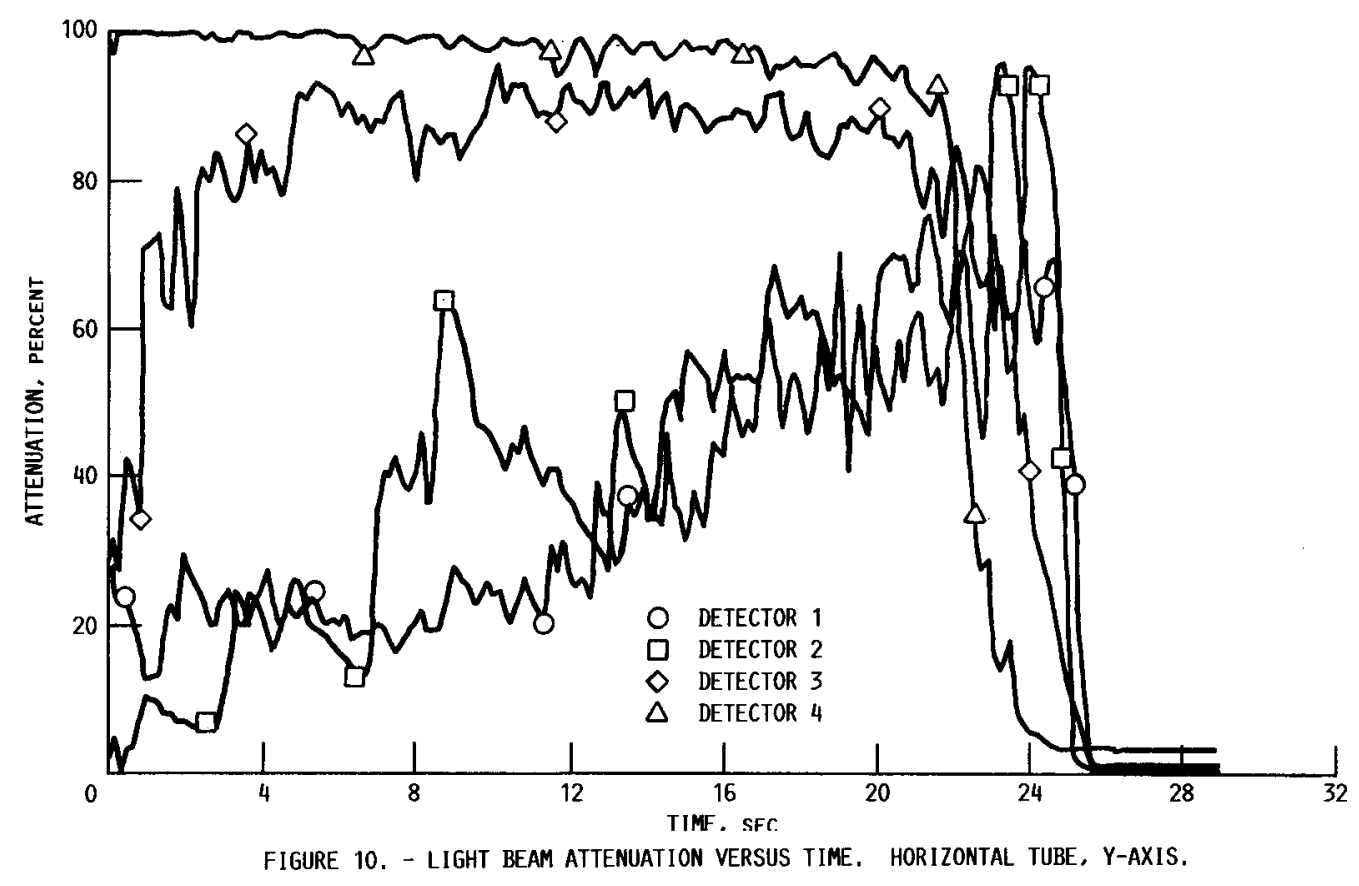




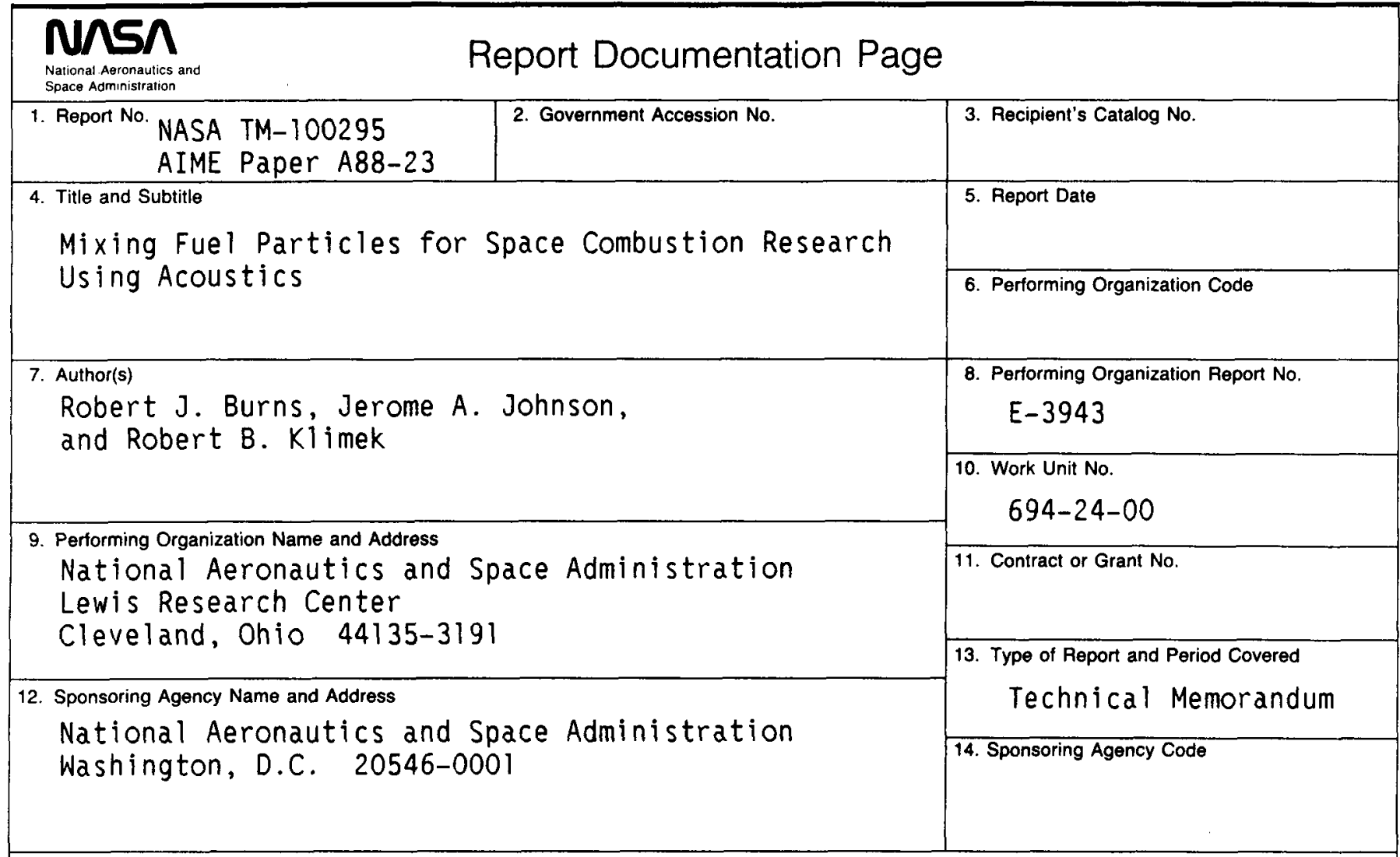

15. Supplementary Notes
Prepared for the Second International Symposium on Experimental Methods for Microgravity Materials Science Research sponsored by the Metallurgical Society of AIME, Phoenix, Arizona, January 25-29, 1988.

16. Abstract

Part of the microgravity science to be conducted aboard the Shuttle (STS) involves combustion using solids, particles, and liquid droplets. The central experimental facts needed for characterization of premixed quiescent particle cloud flames cannot be adequately established by normal gravity studies alone. This paper describes the experimental results to date of acoustically mixing a prototypical particulate, lycopodium, in a $5 \mathrm{~cm}$ diameter by $75 \mathrm{~cm}$ long flame tube aboard a Learjet aircraft flying a 20-sec low-gravity trajectory. Photographic and light detector instrumentation combine to measure and characterize particle cloud uniformity.

17. Key Words (Suggested by Author(s))

Microgravity facilities

Acoustic mixing of particles

Particle detection

18. Distribution Statement

Unclassified - Unlimited

Subject Category 14

19. Security Classif. (of this report)

Unclassified

20. Security Classif. (of this page)

Unclassified

21. No of pages

22. Price ${ }^{*}$

A02. 